\title{
ARTICLE
}

\section{Identification of novel mouse and rat CB1R isoforms and in silico modeling of human CB1R for peripheral cannabinoid} therapeutics

\author{
Qing-Rong Liu ${ }^{1}$, Nicholas S. Huang ${ }^{1}$, Hong $\mathrm{Qu}^{2}$, Jennifer F. O'Connell ${ }^{1}$, Isabel Gonzalez-Mariscal ${ }^{1}$, Sara Santa-Cruz-Calvo ${ }^{1}$, \\ Maire E. Doyle ${ }^{1}$, Zheng-Xiong. $\mathrm{Xi}^{3}$, Yun Wang ${ }^{4}$, Emmanuel. S. Onaivi ${ }^{5}$ and Josephine M. Egan ${ }^{1}$
}

Targeting peripheral CB1R is desirable for the treatment of metabolic syndromes without adverse neuropsychiatric effects. We previously reported a human $\mathrm{hCB} 1 \mathrm{~b}$ isoform that is selectively enriched in pancreatic beta-cells and hepatocytes, providing a potential peripheral therapeutic hCB1R target. It is unknown whether there are peripherally enriched mouse and rat CB1R (mCB1 and $\mathrm{rCB} 1$, respectively) isoforms. In this study, we found no evidence of peripherally enriched rodent CB1 isoforms; however, some $\mathrm{mCB} 1 \mathrm{R}$ isoforms are absent in peripheral tissues. We show that the mouse $\mathrm{Cnr} 1$ gene contains six exons that are transcribed from a single promoter. We found that $\mathrm{mCB} 1 \mathrm{~A}$ is a spliced variant of extended exon 1 and protein-coding exon 6 ; mCB1B is a novel spliced variant containing unspliced exon 1 , intron 1, and exon 2, which is then spliced to exon 6 ; and $\mathrm{mCB} 1 \mathrm{C}$ is a spliced variant including all 6 exons. Using RNAscope in situ hybridization, we show that the isoforms mCB1A and mCB1B are expressed at a cellular level and colocalized in GABAergic neurons in the hippocampus and cortex. RT-qPCR reveals that $m C B 1 A$ and mCB1B are enriched in the brain, while $\mathrm{mCB} 1 \mathrm{~B}$ is not expressed in the pancreas or the liver. Rat $\mathrm{rCB} 1 \mathrm{R}$ isoforms are differentially expressed in primary cultured neurons, astrocytes, and microglia. We also investigated modulation of Cnr1 expression by insulin in vivo and carried out in silico modeling of CB1R with JD5037, a peripherally restricted CB1R inverse agonist, using the published crystal structure of hCB1R. The results provide models for future $C B 1 R$ peripheral targeting.

Keywords: cannabinoids; cell- and tissue-based therapy; alternative splicing; gene expression

Acta Pharmacologica Sinica (2019) 40:387-397; https://doi.org/10.1038/s41401-018-0152-1

\section{INTRODUCTION}

The endocannabinoid system consists of two major types of cannabinoid receptors (CBRs), CB1R and CB2R, their endogenous ligands, endocannabinoids, and their synthesizing and degradation enzymes [1]. There is increasing global awareness and interest in the use of cannabis and cannabis products-ligands of the CBRs-for therapeutic (epilepsy and pain management, for example) and recreational purposes. There was also great interest, especially in the first decade of this century, in inhibiting cannabinoid receptor $1(\mathrm{CB} 1 \mathrm{R})$ in the brain. Its inhibition was shown to cause weight loss and therefore became a potential treatment for obesity and type 2 diabetes, two diseases that had recently reached epidemic proportions. However, due to adverse neuropsychiatric effects [2], that strategy was abandoned.

Nonetheless, there was some merit in targeting CB1R inhibition as a viable treatment option. We now know, more than a decade later, that CB1R inhibition in the periphery improves insulin receptor sensitivity in pancreatic beta-cells [3], adipocytes [4], kidney [5], and hepatocytes [6]. Moreover, peripheral CB1R inhibition in adipocytes lessens weight gain in rodents on high- fat diets, demonstrating that central inhibition of CB1R is not the only mechanism by which CB1R inhibition leads to weight loss [7]. CB1R inhibition in macrophages may be beneficial in decreasing the sequelae of inflammatory processes [8, 9]. Therefore, peripherally restricted $C B 1 \mathrm{R}$ inhibitory agents are an alternative to centrally acting inhibitors for the treatment of type 2 diabetes mellitus, obesity, kidney and liver diseases, and chronic inflammatory diseases. It therefore behooves us to carry out an in-depth analysis of the CB1R receptor, with an emphasis on the peripheral tissues.

Rodents typically are the species we study to understand biological actions of compounds. Therefore, we need to understand mouse and rat $\mathrm{Cnr} 1$ gene structures, promoters, alternative splicing, tissue, and cell type-specific expression and translate the rodent findings into properly designed and executed human clinical studies. Cannabinoids have unique pharmacological actions in different species, tissues, and cell types [10]. Phenotypic differences in the endocannabinoid systems of various species are underlined by the differential evolution of cannabinoid receptor genes whose structure, alternative splicing, and expression are

\footnotetext{
'Laboratory of Clinical Investigation, National Institute on Aging, NIH, Baltimore, MD, USA; ${ }^{2}$ Center for Bioinformatics, State Key Laboratory of Protein and Plant Gene Research,

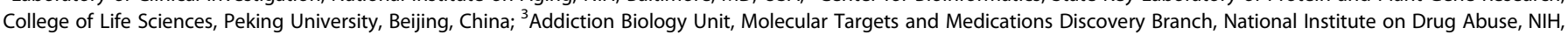

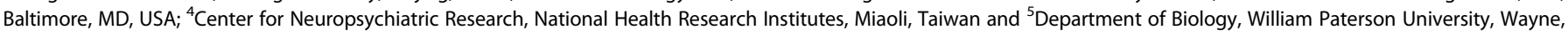
NJ, USA

Correspondence: Qing-Rong Liu (qliu@mail.nih.gov)
}

Received: 15 January 2018 Accepted: 18 June 2018

Published online: 10 September 2018 
species specific [11]. New exon generation and alternative splicing events may play a partial role in the evolutionary branching of CNR1 and CNR2, as observed between mice and rats, and in the evolutionary links between rhesus monkeys and humans [12-14].

We previously reported that species differences exist in CNR2 gene structures, expression, and alternative splicing in humans, mice, and rats $[13,15,16]$. We found that the human CNR2 gene has two separate promoters and four exons that are spliced into hCB2A and hCB2B transcripts. Comparatively, the rodent Cnr2 gene also has two separate promoters. The mouse $\mathrm{Cnr} 2$ gene contains three exons that are spliced to $\mathrm{mCB} 2 \mathrm{~A}$ and $\mathrm{mCB} 2 \mathrm{~B}$ transcripts with a C-terminal premature stop codon, and the rat $C n r 2$ gene contains three exons that are spliced into $\mathrm{rCB} 2 \mathrm{~A}, \mathrm{rCB} 2 \mathrm{~B}$, rCB2C, and rCB2D transcripts [16]. In contrast, the human CNR1 gene has one promoter and four exons that are spliced into six spliced variants [12]. However, rodent Cnr1 gene structures, tissuespecific expression, and splicing patterns are not clearly defined, so their promoters are ambiguous [17]. In this report, we outline the evolutionary branching of mouse and rat Cnrl genes that resulted in their differential splicing and expression in different tissues and cell types. We study the effects of engaging the insulin receptor on expression of $\mathrm{Cnr} 1$, and we model the peripherally restricted CB1R inverse agonist JD5037 [18] on the published human CB1R crystal structure $[19,20]$ and explore potential modifiable moieties for peripheral targeting of CB1R.

\section{MATERIALS AND METHODS}

Animal subjects

Male Long-Evans rats, mice with a C57BL/6J genetic background (Charles River, Raleigh, NC), and beta-cell-specific CB1R-knockout $\left(\beta-C B 1 R^{-/-}\right)$mice were used in this study. They were housed in a fully accredited animal facility and were maintained on a $12 \mathrm{~h}$ light/dark cycle (lights on at 7:00 P.M., lights off at 7:00 A.M.) with food and water ad libitum in the home cage. For diet studies, male wild-type and $\beta$-CB1 $\mathrm{R}^{-1-}$ mice (2-3 months) were fed a standard $\operatorname{diet}$ (SD, $n=4$ for wild-type (WT) mice; $16.7 \%$ kcal fat and $12.4 \%$ kcal sugar) or high-fat, high-sugar diet (HFHS, $n=6$ for wild-type and $n=6$ for $\beta-C B 1 R^{-1-}$ mice; $49.2 \% \mathrm{kcal}$ fat and $32.2 \% \mathrm{kcal}$ sugar from Dyets, Inc.) for 15 weeks to induce obesity. At the end of the study, body weight (WT-SD: $35.1 \pm 0.52$; WT-HFHS: $63.6 \pm 1.76$; and $\beta-C B 1 R^{-1-}$-HFHS: $55.6 \pm 4.02$ in grams with standard deviation), liver weight (WT-SD: $1.7 \pm 0.21$; WT-HFHS: $5.7 \pm 0.44$; and $\beta$-CB1R ${ }^{-1-}$-HFHS: $3.9 \pm 0.77$ in grams with standard deviation), subcutaneous fat (WT-SD: $0.8 \pm 0.19$; WT-HFHS: $4.0 \pm 1.51$; and $\beta-C B 1 R^{-1}-$ HFHS: $3.8 \pm 0.58$ in grams with standard deviation), visceral fat (WT-SD: $1.0 \pm 0.22$; WT-HFHS: $2.1 \pm 0.47$; and $\beta-C B 1 R^{-1-}$-HFHS: $1.7 \pm 0.38$ in grams with standard deviation), and blood glucose (WT-SD: $159.0 \pm 4.24$; WT-HFHS: $143.5 \pm 16.25$; and $\beta-C B 1 R^{-1-}$-HFHS: $149.3 \pm 20.53$ in $\mathrm{mg} / \mathrm{dL}$ with standard deviation) were measured. To generate an acute insulin resistance model, adult (8-12 weeks old) C57BL/6J male mice were continuously infused (flow rate $1 \mu \mathrm{L} / \mathrm{h}$ ) with $10 \mathrm{nM}$ of a peptidebased insulin receptor antagonist $(S 961, n=6)$ or vehicle (phosphate-buffered saline, $n=7$ ), for 7 days by using $200 \mu \mathrm{L}$ reservoir micro-osmotic pumps (Alzet Model 2001, Cupertino, CA, USA) according to Alzet guidelines (http://www.alzet.com). Micro-osmotic pumps were prepared following the manufacturer's instructions and subcutaneously implanted in mice previously anesthetized following the National Institutes of Health (NIH) ethics guidelines. S961 was kindly provided by Novo Nordisk as a gift (Denmark).

Pumping rate was $0.05 \mathrm{nmol}$ of 5961 per hour $(1.2 \mathrm{nmol} /$ day $)$. Blood glucose and insulin levels were measured from tail bleed prior to surgery and daily after surgery until day 6 when the animals were killed and tissues collected. The experimental procedures followed the Guide for the Care and Use of Laboratory Animals (1996) and were approved by the National Institute on
Drug Abuse (NIDA) and the National Institute on Aging (NIA) Animal Care and Use Committees.

Reverse transcription polymerase chain reaction (RT-qPCR) analysis

Total RNAs were isolated from various brain regions and peripheral tissues using the TRIzol Reagent (Thermo Fisher Scientific, Waltham, MA, USA). Single-strand complementary DNAs (cDNAs) were synthesized using the Superscript III first-strand cDNA synthesis kit (Invitrogen, Life Technologies, Carlsbad, CA, USA). TaqMan probes at the splicing junctions (Fig. 1 and Table 1) were designed using Primer Express 3.0 (Applied Biosystems, Life Technologies, Carlsbad, CA, USA). Mouse vic-labeled Actb and rat vic-labeled Gapdh (Table 1) were used as endogenous controls. Duplex PCR assays containing both the target and endogenous control TaqMan probes were carried out with Advanced TaqMan Fast PCR Master Mix in StepOnePlus instrument using a default thermocycling program. The relative fold change was calculated using the formula: $2 \wedge^{(-\triangle \triangle \mathrm{Ct})}[21]$.

Primary cultures of rat neurons, astrocytes, and microglia Primary cell cultures were prepared from embryonic (E14-15) cortex tissues obtained from fetuses of timed-pregnant SpragueDawley rats as previously described [22]. The olfactory bulbs, striatum, and hippocampus were removed aseptically, and cortices were dissected. After removing the blood vessels and meninges, pooled cortices were trypsinized ( $0.05 \%$; Invitrogen, Carlsbad, CA) for $20 \mathrm{~min}$ at room temperature. After removing trypsin by washing with prewarmed Dulbecco's modified Eagle's medium (DMEM; Thermo Fisher Scientific, Waltham, MA, USA), cells were dissociated by trituration, counted, and plated into 96-well $(5.0 \times$ 104 well) cell culture plates precoated with poly-D-lysine hydrobromide (Sigma-Aldrich, St. Louis, MO, USA). The culture plating

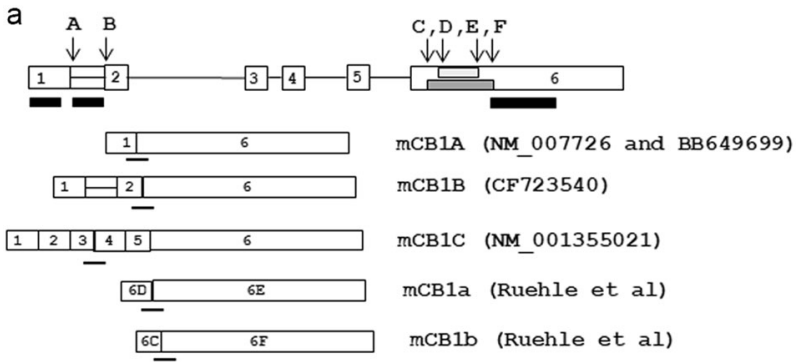

b
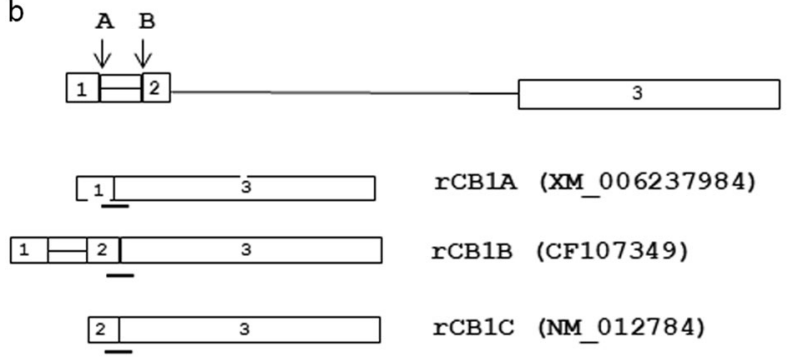

Fig. 1 a Mouse $C n r 1$ (4A5) and b rat $C n r 1$ gene (5q21) structure and transcript variants. The open boxes represent the exons, with the exon number marked inside the box, and horizontal lines represent introns. A fused exon-intron is shown by an open box with a middle line. The intra-exonal introns are shown by smaller shaded boxes, and arrows represent intra-exonal splicing sites. The alternatively spliced transcript variants are shown under the genes, and GenBank accession numbers are included in the parenthesis. The TaqMan probes were designed to hybridize in junctions of spliced exons represented by thin lines under exon-exon junctions. RNAscope ZZ pair probes are marked as black bars under exon 1, retaining intron 1 and the $3^{\prime}$ UTR of the mouse Cnrl gene 


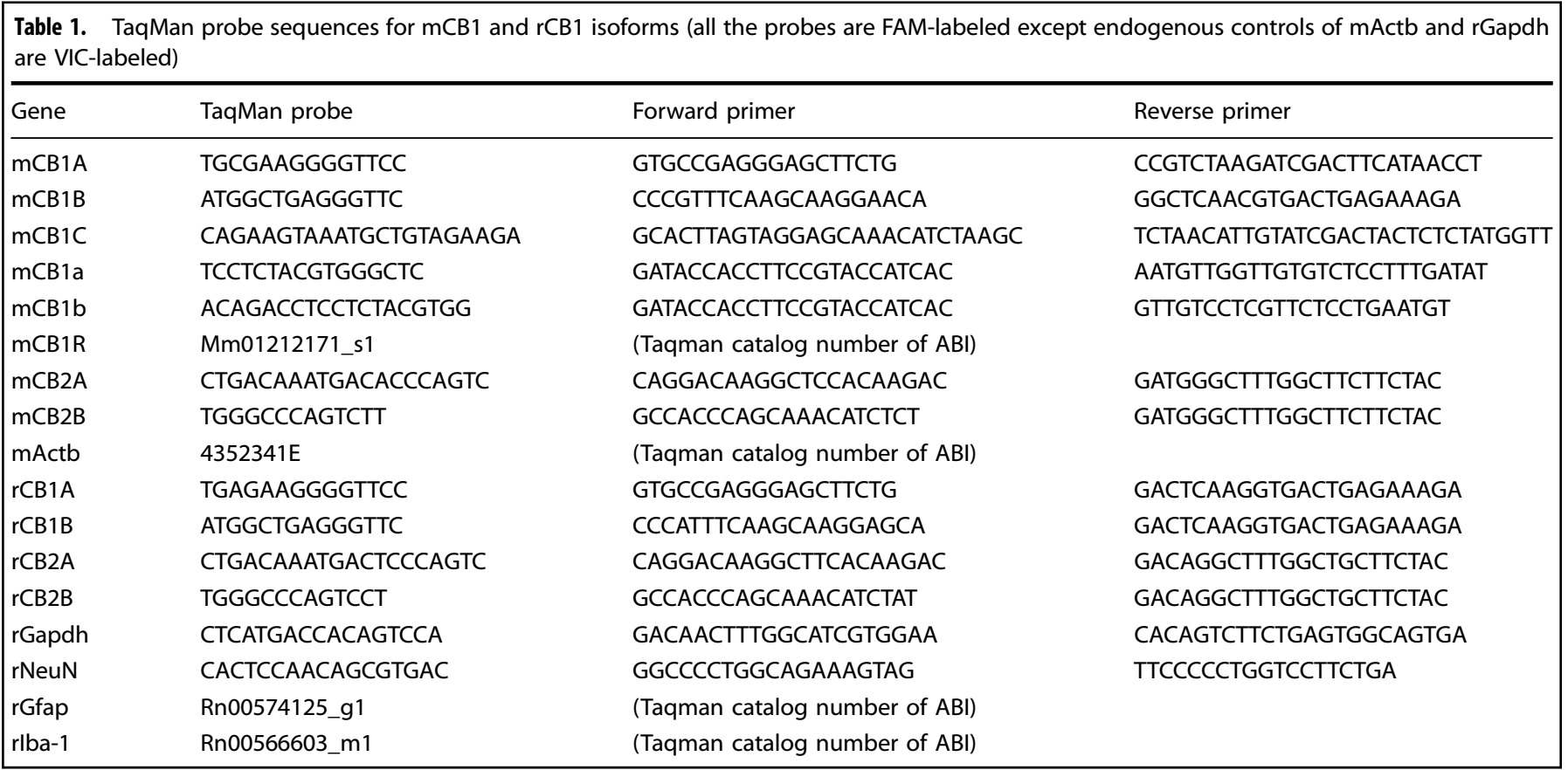

medium consisted of neurobasal medium supplemented with $2 \%$ heat-inactivated fetal bovine serum (FBS), $0.5 \mathrm{mM}$ L-glutamine, $0.025 \mathrm{mM} \mathrm{L-glutamate}$, and 2\% B27 (Thermo Fisher Scientific, Waltham, MA, USA). Most of the primary culture was now neurons, and it was maintained at $37{ }^{\circ} \mathrm{C}$ in a humidified atmosphere of $5 \%$ $\mathrm{CO}_{2}$ and $95 \%$ air. After $24 \mathrm{~h}$, the culture medium was replaced with DMEM/F12/FBS medium, which was exchanged every 3 days. At 10 or 12 days after plating, the cultures consisted of both astrocytes and microglial cells in different layers. Microglia were collected with $0.125 \%$ trypsin without EDTA, and astrocytes were obtained by 8 days of culture [23].

RNAscope in situ hybridization (ISH)

RNAscope ISH probes (Fig. 1) were custom designed by Advanced Cell Diagnostics Inc. (ACD, Hayward, CA, USA) for mCB1A (16 ZZ pairs targeting 104-1097 of AK163855 within extended exon 1), mCB1B (20 ZZ pairs targeting 1517-2779 of AY522555 within intron 1) in the $C 1$ channel and the common $m C B 1 R$ in the $C 2$ channel (20 ZZ pairs targeting 530-1458 of NM_007726 within coding exons). A mouse Gad1 probe in $C 2$ was ordered from ACD (ACD, Hayward, CA, USA). Mouse brains were rapidly frozen in $100 \mathrm{~mL},-50^{\circ} \mathrm{C}$ isopentane, then placed in powdered dry ice and stored at $-80^{\circ} \mathrm{C}$ in a sealed bag. The cryostat sectioning, fixation, protease pretreatment, probe hybridization, preamplification, amplification, and fluorescent labeling steps have been described previously [16]. A Zeiss LSM 880 confocal microscope was used to image fluorescent labeling.

\section{Data analysis}

GraphPad Prism 6.0 software was used for statistical analysis, and data are presented as the means \pm SEM. We compared differences between mean values for variables of controls and experiments statistically by Student's $t$-test and one-way analysis of variance (ANOVA) included in the software. A $P$ value of $\leq 0.05$ was considered statistically significant.

\section{Bioinformatics}

Rat and mouse Cnr1 genomic sequences were downloaded from Ensembl genome browser 91 (http://useast.ensembl.org/ Mus_musculus/Info/Index), and the sequences were searched in the mouse and rat EST (expressed sequence tags) databases using the National Center for Biotechnology Information (NCBI) Blastn suite (https://blast.ncbi.nlm.nih.gov/Blast.cgi? PAGE_TYPE=BlastSearch). Homologous RIKEN cap-trapperselected [24] EST sequences and exon-intron junctions were defined by alignment with the genomic sequences using Sequencher software (Gene Codes Corporation, Ann Arbor, MI, USA). The University of California, Santa Cruz (UCSC) Genome Browser Gateway (https://genome.ucsc.edu/cgi-bin/hgGateway) was used to identify CpG islands. The LASAGNA 2.0 (http:// biogrid-lasagna.engr.uconn.edu/lasagna_search/) algorithm [25] was used to search transcription factor binding sites with the $5^{\prime}$ flanking sequence of the mouse Cnr1 transcription start site (TSS) and the transcription factors (TFs) were identified by web framework of JASPAR 2018 database (http://jaspar.genereg.net/) of transcription factors [26]. Integrated miRBase [27] was used to search the mouse Cnr1 $3^{\prime}$ untranslated region (UTR) sequence to identify microRNA (miRNA) targets (http://www.mirbase.org/ search.shtml). SPRAM (a sequence-based $\mathrm{N}^{6}$-methyladenosine $\left(m^{6} A\right)$ modification site predictor) was used to predict potential mammalian N6-methyladenosine (m6A) sites with RNA secondary structures of 5'UTR of mCB1A and mCB1B [28].

The three-dimensional (3D) structures of JD5037 and 2arachidonoylglycerol (2-AG) were built and minimized by using molecular-dynamic calculations in the Insightll package (http:// www.ifm.liu.se/compchem/msi/doc/life/insight2K/insight/v2kTOC. html). The minimized conformations of JD5037 and 2-AG were thus obtained. The crystal structure of the human CB1R was downloaded from the Protein Data Bank (PDB) database (PDBID: 5TGZ). The Chimera software program was used to delete the ligands, $\mathrm{H}$-atoms, and crystallized water molecules [29]. The Autodock 4.2 package [30] was used to perform ligand-receptor docking. In the setting of the parameters for docking, the ligand adopts a flexible conformation, and the receptor adopts fixed conformation. Through the analysis of the results of the docking simulation, a low-binding-energy conformation of ligand-receptor was selected. Based on the simulated interaction of ligand and receptor, we divided JD5037 into four arms and 2-AG into an approximate ring with a hydrophilic head and a hydrophobic tail [20]. 
Table 2. Tissue expression levels of $\mathrm{mCB} 1$ isoforms (fold of cortex $\mathrm{mCB} 1 \mathrm{R}, n=4$ )

\begin{tabular}{|c|c|c|c|c|c|c|c|c|}
\hline Isoforms & Cortex & Cerebellum & Hippocampus & Hypothalamus & Midbrain & Pancreas & Muscle & Liver \\
\hline $\mathrm{mCB} 1 \mathrm{R}$ & 1.0638 & 8.1207 & 0.9394 & 3.3746 & 0.9331 & 0.0478 & 0.2488 & 0.0024 \\
\hline $\mathrm{mCB} 1 \mathrm{~A}$ & 1.9253 & 8.7186 & 4.1779 & 4.9406 & 1.6058 & 0.0293 & 0.0369 & 0.0003 \\
\hline $\mathrm{mCB} 1 \mathrm{~B}$ & 0.3254 & 2.3050 & 0.4342 & 1.0216 & 0.3014 & 0.0000 & 0.0034 & 0.0000 \\
\hline $\mathrm{mCB} 1 \mathrm{C}$ & 0.0108 & 0.0508 & 0.0087 & 0.0234 & 0.0048 & 0.0039 & 0.0000 & 0.0000 \\
\hline mCB1a & 0.0039 & 0.0170 & 0.0025 & 0.0078 & 0.0025 & 0.0000 & 0.0090 & 0.0000 \\
\hline $\mathrm{mCB} 1 \mathrm{~b}$ & 0.0000 & 0.0023 & 0.0006 & 0.0009 & 0.0000 & 0.0000 & 0.0000 & 0.0000 \\
\hline rCB1A & 1.0150 & 4.3829 & 1.8773 & 0.9639 & 0.6732 & 0.0241 & 0.0465 & 0.0277 \\
\hline
\end{tabular}
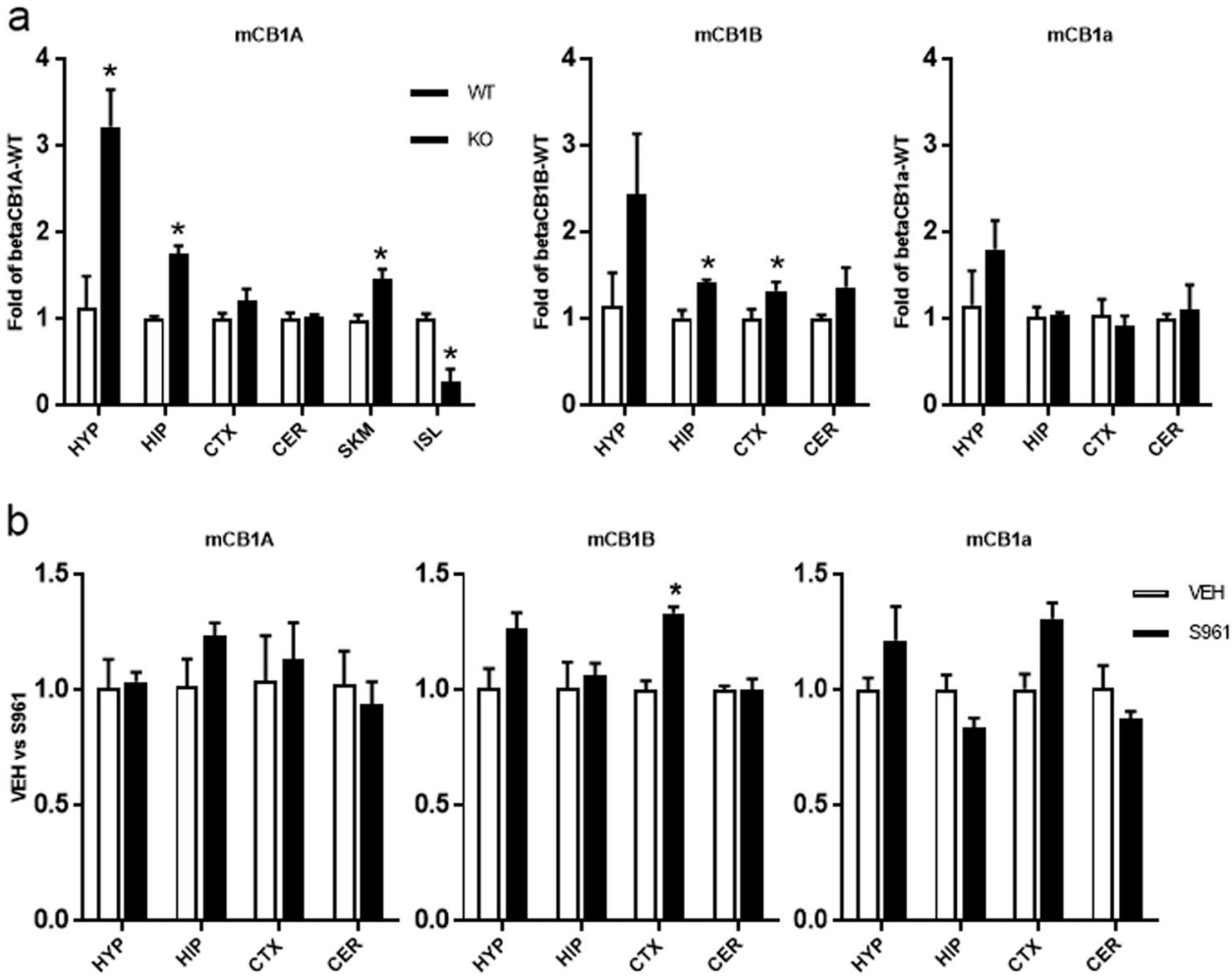

C
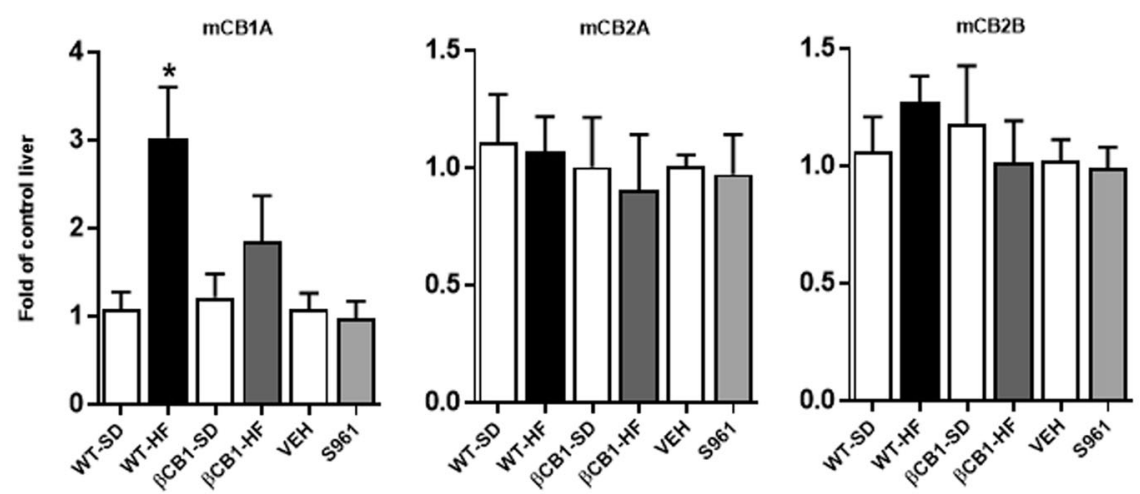

Fig. 2 a Hypothalamus (HYP), hippocampus (HIP), cortex (CTX), cerebellum (CER), skeletal muscle (SKM), and islet (ISL) expression of mCB1A, mCB1B, and mCB1a in wild-type and beta-cell CB1R-knockout mice (strain background: C57BL/6). One-way ANOVA ( $n=4$, the mean \pm SEM, $\left.{ }^{*} P<0.05\right)$. $\mathbf{b}$ Expression of $\mathrm{mCB1A}, \mathrm{mCB} 1 \mathrm{~B}$, and $\mathrm{mCB} 1 \mathrm{a}$ in hypothalamus (HYP), hippocampus (HIP), cortex (CTX), and cerebellum (CER) of mice

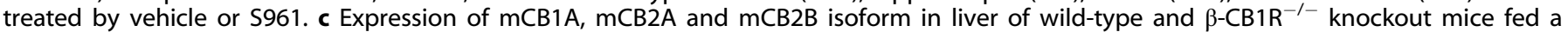
standard (SD) or high-fat (HF) diet, and in liver of wild-type mice treated with vehicle or S961. Unpaired Student's $t$-test between control and experimental groups $\left(n=4\right.$, the mean \pm SEM, $\left.{ }^{*} P<0.05\right)$. The $y$-axis is fold change of mCB1R isoforms in tissues of $\beta$-CB1-KO using the relevant wild-type mouse tissue as reference (a), vehicle vs $S 961$ (b, c), and standard diet vs high-fat diet (c) 
a

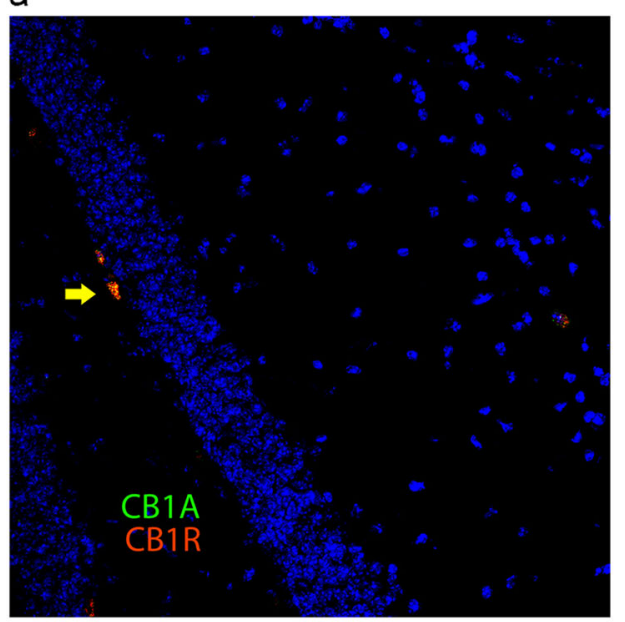

C

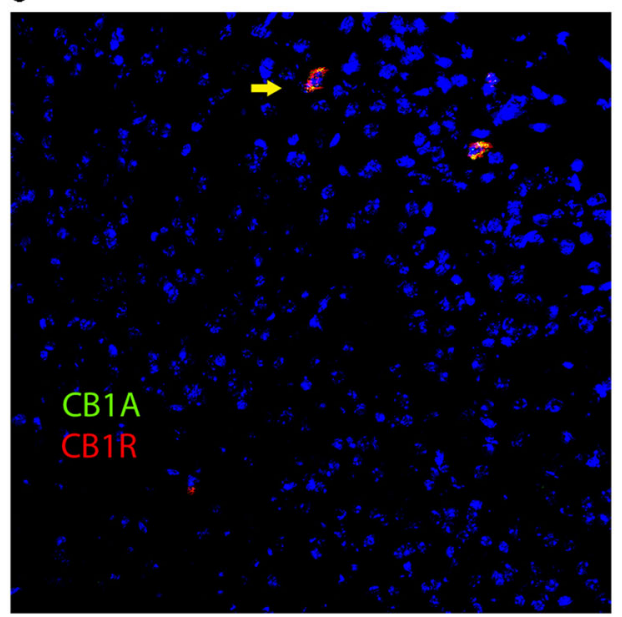

b

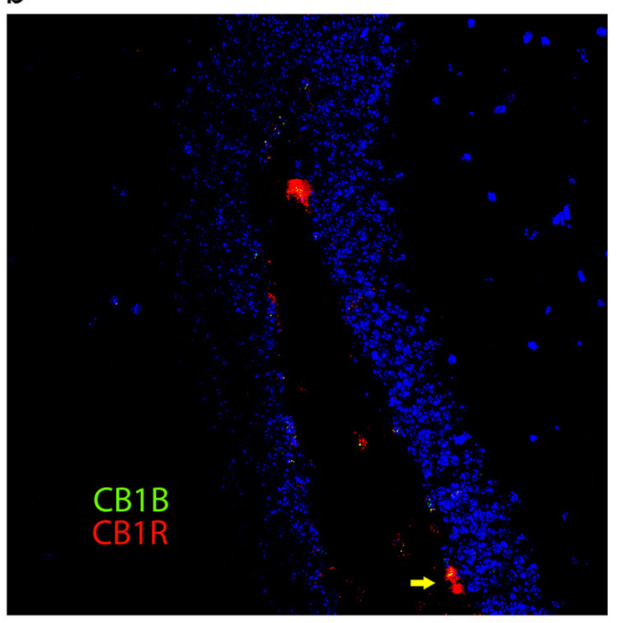

d

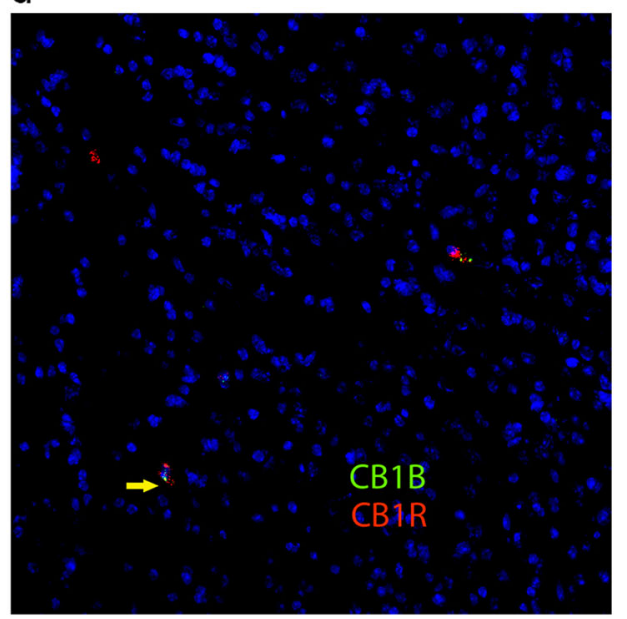

Fig. 3 RNAscope ISH colocalization $(20 x)$ of $m C B 1 A$ and $m C B 1 B$ isoform-specific probes with the common $C B 1 R$ probe in mouse brain. $\mathrm{mCB} 1 \mathrm{~A}$ and $\mathrm{mCB} 1 \mathrm{~B}$ probes (green) hybridize with mCB1R (red) positive cells in hippocampus (a mCB1A; b mCB1B) and cortex (c mCB1A; d $\mathrm{m} C \mathrm{~B} 1 \mathrm{~B})$. Yellow arrows indicate the colocalization of $\mathrm{mCB} 1$ isoforms with the common mCB1 probe

\section{RESULTS}

Novel mouse Cnr1 gene isoforms, tissue, and cell type expression The mouse Cnrl gene was previously found to have two exons, with the second exon encoding the entire open reading frame [31], while its promoter region remains undefined [32]. mCB1A is represented by NM_007726 in the Reference Sequence (RefSeq) database [33], with exon 1 spliced to the coding exon 6 (Fig. 1a). We used the upstream $1 \mathrm{~kb}$ genomic sequence of NM_007726 to blast the NCBI expressed mouse sequence tag database (dbEST) and found that RIKEN cap-trapper-selected [24] EST clones of BB649699, AK163855, and CK781273 aligned to the blasted sequence. The EST sequences extended $584 \mathrm{bp}$ upstream of NM_007726, so that mCB1A contained a 1173 bp 5'UTR sequence with the cap structure (Fig. 1a). mCB1B was represented by the full-length enriched RIKEN EST clone AK163855 and IMAGE mouse CDNA clones CCD803018 and CF723540 [34], which aligned with mouse Cnr1 exon 1, intron 1, exon 2, and exon 6. Therefore, mCB1B contained a $2711 \mathrm{bp} 5^{\prime}$ UTR sequence with the cap structure (Fig. 1a). mCB1C is represented by NM_001355021, which includes all six exons and $1551 \mathrm{bp}$ of the $5^{\prime}$ UTR sequence (Fig. 1a). Together with two additional intra-exon-6 splicing isoforms of mCB1a and $\mathrm{mCB} 1 \mathrm{~b}$ [35], there were at least five $\mathrm{mCB} 1$ isoforms (Fig. 1a). Since exons 1 and 2 were separated by the $1451 \mathrm{bp}$ of intron 1 and exons 1 and 6 were separated by
$18,470 \mathrm{bp}$, the mouse Cnr1 promoter was likely located upstream of the extended exon 1.

We designed TaqMan probes and primers (Table 1) across exon junctions of $\mathrm{mCB} 1 \mathrm{~A}$ (exons 1 and 6), $\mathrm{mCB} 1 \mathrm{~B}$ (exons 2 and 6), $\mathrm{mCB} 1 \mathrm{C}$ (exons 3 and 4), mCB1a (exons $6 \mathrm{D}$ and $6 \mathrm{E}$ ), and $\mathrm{mCB} 1 \mathrm{~b}$ (exons 6C and 6F) (Fig. 1a). RT-qPCR experiments were performed in mouse brain regions and peripheral tissues $(n=3)$ using mouse beta-actin as an endogenous control (Tables 1 and 2). Messenger RNA (mRNA) relative fold changes were calculated with the

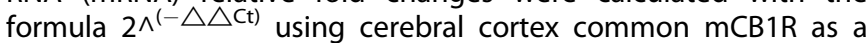
reference [21]. Table 2 shows that $\mathrm{mCB} 1 \mathrm{~A}$ and $\mathrm{mCB} 1 \mathrm{~B}$ were the predominant isoforms, with a brain-region rank order of cerebellum, hypothalamus, hippocampus, cortex, and midbrain. We observed low peripheral expression (100s-fold less than those of brain) of $m C B 1 A$ and $m C B 1 C$ in total pancreas; $m C B 1 A$ in the liver; and $\mathrm{mCB} 1 \mathrm{~A}, \mathrm{mCB} 1 \mathrm{~B}$, and $\mathrm{mCB} 1 \mathrm{a}$ in skeletal muscle. The expression of $m C B 1 A$ was approximately 4-10 times higher than that of $\mathrm{mCB} 1 \mathrm{~B}$ in brain regions and hundreds to thousands of times higher than those of mCB1C, mCB1a, and mCB1b (Table 2).

We previously reported that pancreatic beta-cell-specific mCB1knockout mice $\left(\beta-C B 1 R^{-1-}\right.$ ) exhibit resistance to beta-cell damage induced by a HFHS diet, and the mice also have peripheral hyperinsulinemia that results in insulin resistance in the liver, in 


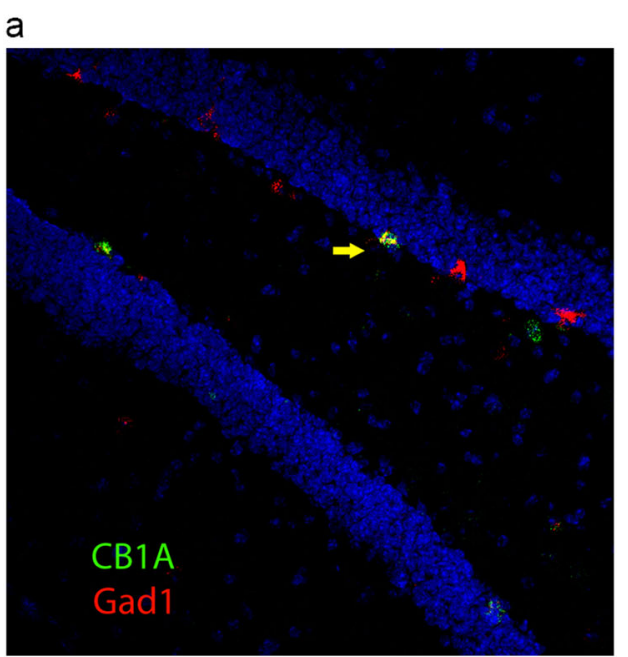

C

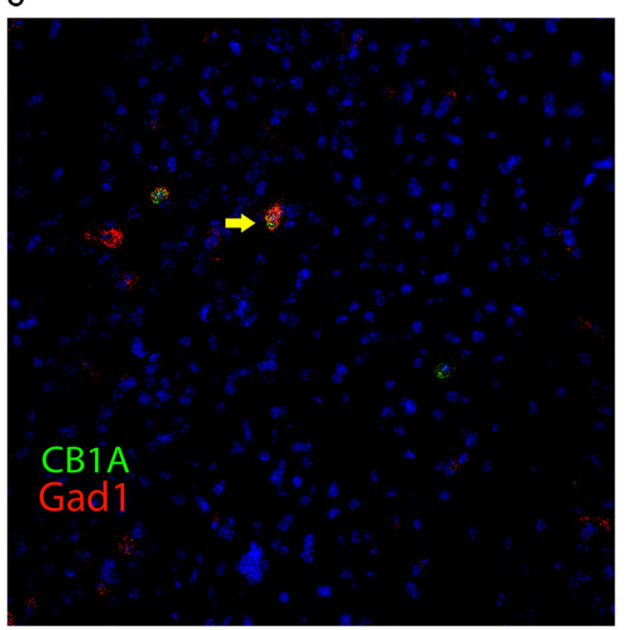

e

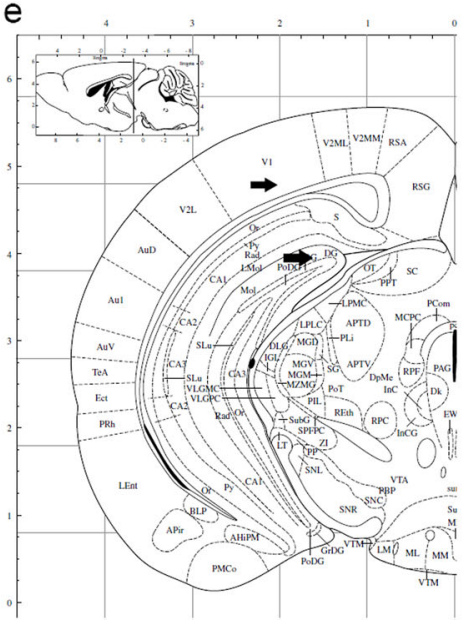

b

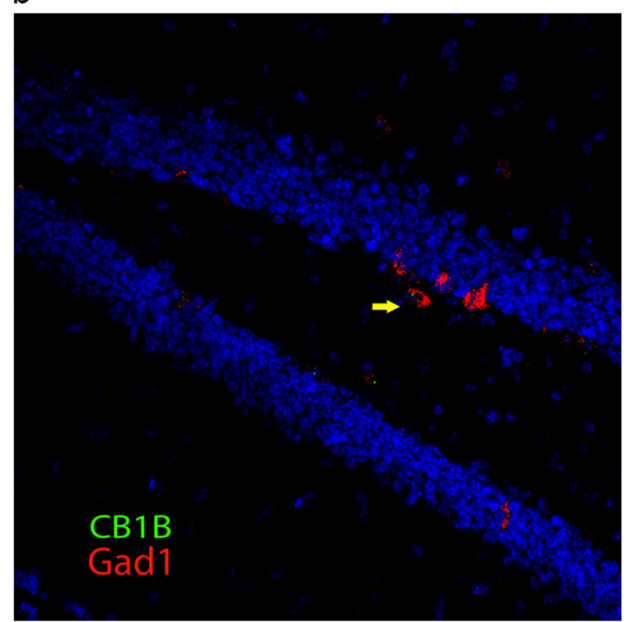

d

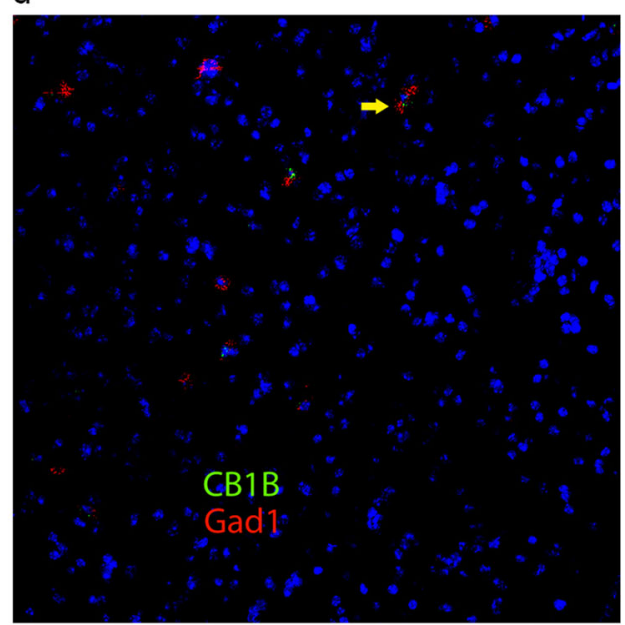

Fig. 4 RNAscope ISH colocalization (20x) of $m C B 1 A$ and $m C B 1 B$ isoform-specific probes (green) with the GABAergic Gad1 (red) probe in hippocampus (a mCB1A; b mCB1b) and cortex (c mCB1A; d mCB1B). Yellow arrows indicate the colocalization of mCB1 isoforms with Gad1. Corresponding hippocampus and cortex stereotaxic coordinates are shown by black arrows (e)

contrast to wild-type mice [36]. We now report that $\mathrm{mCB1A}$ and mCB1B were upregulated in the hypothalamus, hippocampus, cortex, and skeletal muscles of the $\beta-C B 1 R^{-1-}$ mice (Fig. 2a). No expression changes in mCB1a were found in those tissues (Fig. 2a). To further clarify whether the brain mCB1R expression is influenced by insulin receptor signaling, we treated both the wild-type and the knockout mice with the insulin receptor antagonist $\mathrm{S} 961$ for 7 days to inhibit insulin action, and we then performed an RT-qPCR assay on multiple tissues. We found no significant change in $\mathrm{mCB} 1 \mathrm{~A}, \mathrm{mCB} 1 \mathrm{~B}$, or $\mathrm{mCB} 1 \mathrm{a}$ in hypothalamus, hippocampus, or cerebellum. However, there was minor upregulation of $\mathrm{mCB} 1 \mathrm{~B}$ and $\mathrm{mCB} 1 \mathrm{a}$ in cortex, indicating the upregulation of 

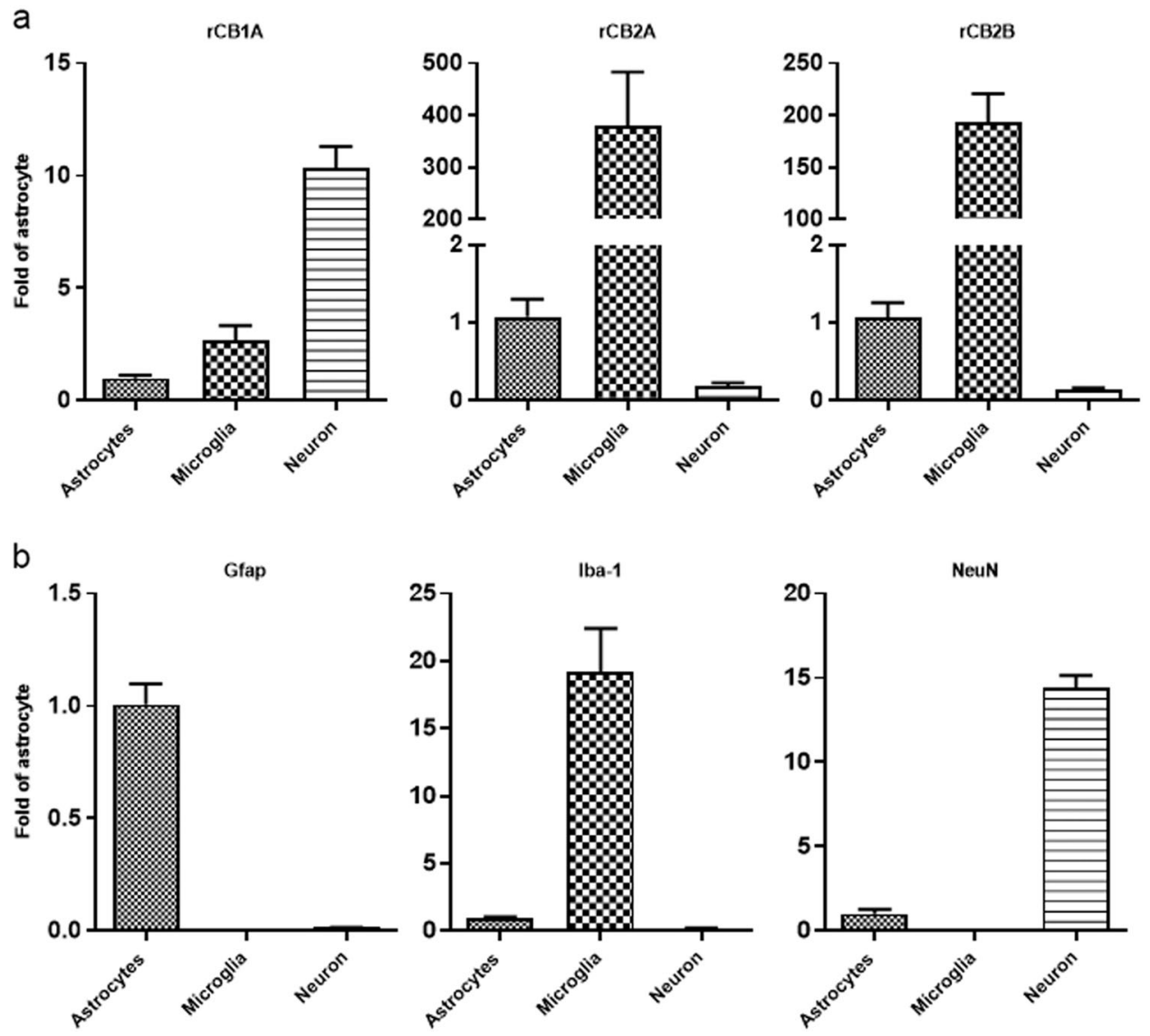

Fig. $5 \mathrm{rCB} 1 \mathrm{~A}, \mathrm{rCB} 2 \mathrm{~A}$, and $\mathrm{rCB} 2 \mathrm{~B}$ cell type expression. a $\mathrm{rCB} 1 \mathrm{~A}, \mathrm{rCB} 2 \mathrm{~A}$, and $\mathrm{rCB} 2 \mathrm{~B}$ expression in rat astrocytes, microglia, and neurons; b astrocyte marker Gfap, microglia marker Iba-1, and neuron marker NeuN expression in rat astrocytes, microglia, and neurons $(n=3$, mean \pm SEM). The $y$-axis is fold change of rCB1A, rCB2A, rCB2B, NeuN, Gfap, and lba-1 gene expression in different primary cell types using the corresponding astrocyte gene as reference

$\mathrm{mCB} 1 \mathrm{~A}$ in the knockout mice was at least partially dependent on insulin receptor signaling (Fig. 2b). Additionally, we found that a HFHS diet increased mCB1A expression only in the livers of wildtype mice and not in the livers of the $\beta-C B 1 R^{-1-}$ mice or S961treated mice. No changes were observed in $\mathrm{mCB} 2 \mathrm{~A}$ or $\mathrm{mCB} 2 \mathrm{~B}$ expression under the standard or HFHS diet in the livers either of the wild-type or $\beta-C B 1 R^{-1-}$ mice (Fig. $2 \mathrm{c}$ ).

Since the $5^{\prime} \mathrm{UTR}$ sequences of $\mathrm{mCB} 1$ isoforms are unusually large (1.2-2.7 kb), we designed RNAscope ISH probes to the novel extended exon 1 (16 ZZ pairs targeting 104-1097 of AK163855), the retaining intron 1 (20 ZZ pairs targeting 1517-2779 of AY522555), and the coding exon 6 (20 ZZ pairs targeting 530-1458 of NM_007726) to confirm their brain cell-type expression (Fig. 1a). We found the complete overlapping of $\mathrm{mCB} 1 \mathrm{~A}$ and $\mathrm{mCB} 1 \mathrm{~B}$ localization with the common mCB1R probe in hippocampus and cortex (Fig. 3a-d), indicating that the isoforms existed at the cellular level. Both the mCB1A and mCB1B mRNAs colocalized with Gad1-positive GABAergic neurons in hippocampus dentate gyrus and primary visual cortex (Fig. 4a-d). The intensity of the hybridization signals indicated that $\mathrm{mCB} 1 \mathrm{~A}$ expression was higher than that of mCB1B in GABAergic neurons in hippocampus and cortex, in agreement with the RT-qPCR data (Table 2).

Novel rat $\mathrm{Cnr} 1$ gene isoforms, tissue, and cell type expression Similarly, the rat Cnrl gene was previously found to have two exons, with the second exon encoding the entire open reading frame [37], while its promoter region remained undefined [37].
The predicted NCBI RefSeq XM_006237984 aligned to mouse Cnr1 exon 1, and NM_012784 [38] aligned to mouse Cnr1 exon 2 (Fig. 1b). Furthermore, rat EST clones of CF107349, BE121087 and BE402651 aligned to intron 1, implying an intron-retaining rCB1B isoform (Fig. 1b). We could not find any mouse Cnr1 exon 4 or exon 5 homologies with the rat $\mathrm{Cnr} 1$ genomic sequence, so we predicted that the rat $C n r 1$ gene contains 3 exons that encode rCB1A and rCB1B (Fig. 1b). The RIKEN cap-trapper-selected mCB1B exon 1 aligned to $\mathrm{rCB} 1 \mathrm{~A}$ and $\mathrm{rCB} 1 \mathrm{~B}$, so it is possible that $\mathrm{rCB} 1 \mathrm{~A}$ contains a 1173 bp 5'UTR and rCB1B contains a 2727 bp 5'UTR, with possible rat cap structures. rCB1C (NM_012784) [31] might represent a truncated mRNA of $\mathrm{rCB} 1 \mathrm{~B}$ (Fig. $1 \bar{b}$ ).

Since rat $C n r 1$ exon 1 and exon 2 were separated by intron 1 (1468 bp) and exon 2 and exon 3 were separated by intron 2 $(16,707 \mathrm{bp})$, the gene promoter was likely localized upstream of exon 1. We designed TaqMan probes that specifically hybridized to the novel rCB1A and $\mathrm{rCB} 1 \mathrm{~B}$ (Table 1). RT-qPCR demonstrated that the rCB1A expression pattern was like that of mCB1A except that its expression in the liver was higher than that of $\mathrm{mCB} 1 \mathrm{~A}$ (Table 2). We further tested $\mathrm{rCB} 1 \mathrm{~A}$ expression in isolated rat primary cell culture of neurons, astrocytes, and microglia and found that $\mathrm{rCB} 1 \mathrm{~A}$ was enriched in neurons but also expressed at low levels in astrocytes and microglia (Fig. 5a). The identities of neurons, astrocytes, and microglia were verified by the neuronal marker NeuN, astrocyte marker Gfap, and microglia marker Iba-1, respectively (Fig. $5 b-d$ ). In contrast, rCB2A and rCB2B were enriched in microglia but also expressed at low levels in astrocytes and neurons (Fig. 5e, f). 
a<smiles>CC(C)[C@H](N/C(=N\S(=O)(=O)c1ccc(Cl)cc1)N1C[C@@H](c2ccccc2)C(c2ccc(Cl)cc2)=N1)C(N)=O</smiles>

C

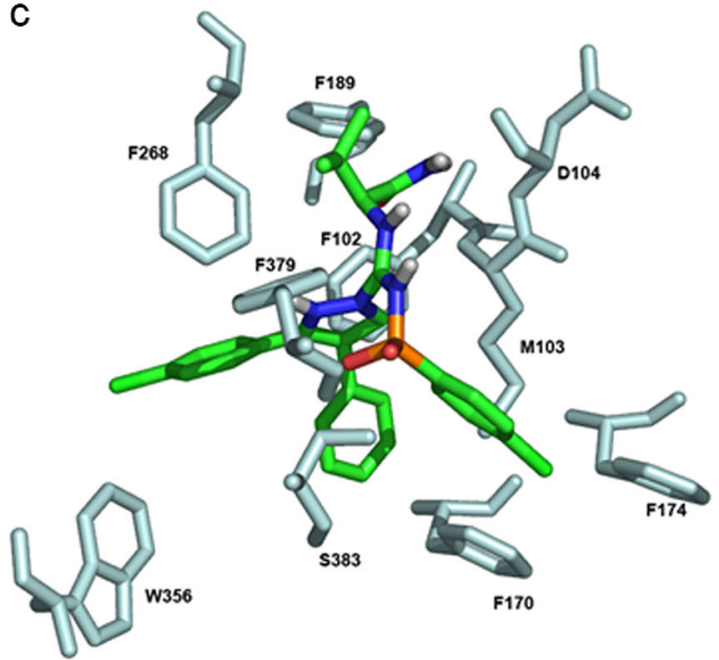

b<smiles>CCCCC/C=C\C/C=C\C/C=C\C/C=C\CCCC(=O)OC(CO)CO</smiles>

d

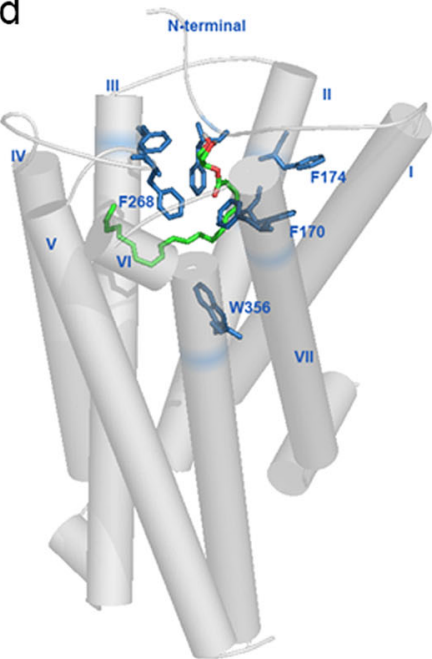

Fig. 6 Chemical structures of JD5037 (a) and 2-AG (b) and predicted interactions of hCB1R with JD5037 (c) and 2-AG (d). JD5037 and 2-AG are indicated by green, red, and blue sticks. The key residues in hCB1R that interact with JD5037 and 2-AG are indicated by light blue

In silico modeling of hCB1R in complex with peripheral restricted hCB1R inverse agonist JD5037

The crystal structures of human CB1R in complex with antagonist AM6538 [20] at $2.8 \AA$ A resolution, inverse agonist MK0364 [38] at 2.6 $\AA$ resolution, and agonists AM11542 and AM841 [19] at $2.80 \AA$ and $2.95 \AA$ resolution, respectively, have been recently published [19, $20,39]$. The X-ray crystallography work on CB1R allowed us to construct in silico the docking complex model of human CB1R with peripheral restricted hCB1R inverse agonist JD5037. We compared the conformation of JD5037 in the binding sites of hCB1R with those of $A M 6538$ and rimonabant, the only CB1R inverse agonist ever to be used for therapeutic purposes in humans [20,39]. The conformation of JD5037 was more flexible and could be divided into four arms (Fig. 6a). The position and direction of JD5037 three arms with benzene rings contacting hCB1R agreed with those in the AM6538 [20] and rimonabant [39] structures. Arm 1 of JD5037 was close to PHE102, MET103, PHE170, and SER383, and these residues formed the side pocket, as mentioned in the crystal structure of hCB1R in complex with AM6538 [20]. The benzene ring in arm 1 contributed $\pi-\pi$ interactions with the benzene rings of PHE102 and PHE170. Arm 2 formed hydrophobic interactions with LEU193, VAL196, PHE268, TRP356, LEU359, and PHE379, and these residues formed the long channel. The chlorobenzene ring in arm 2 contributed $\pi-\pi$ interactions with PHE268 and PHE379. Arm 3 formed hydrophobic interactions with MET103, PHE170, PHE174, ALA380, and SER383, and these residues formed a gap. The chlorobenzene ring in arm 3 contributed $\pi-\pi$ interactions with PHE170 and PHE174. The hydrogen bond between arm 3 and SER383 was detected in the docking model. Arm 4 formed hydrophobic interactions with ASN101, MET103, ASP104, ILE105, PHE189, ILE267, and PRO269, as well as hydrogen bonds with ASN101 and MET103 (Fig. 6c). Arm 4 was in the entrance of the binding pocket, with a partial protrusion into the pocket.

The conformation of the 2-AG molecule showed that it folded to form an approximate ring with a hydrophilic head and a hydrophobic tail (Fig. 6b). The folding annular part of 2-AG molecule was hydrophobic and interacted with the side pocket near TM-VI and -VII of hCB1R. The interaction mode of the folding annular part of 2-AG was equivalent to arm 1 of JD5037. The hydrophilic head of 2-AG behaved in a similar way to arm 3 of JD5037 and extended into the gap enclosed by the N-terminal loop and TM-II, and the hydrophobic tail of 2-AG behaved similarly to arm 2, extending into the long channel enclosed by TM-III, -V, and -VI (Fig. 6d). 


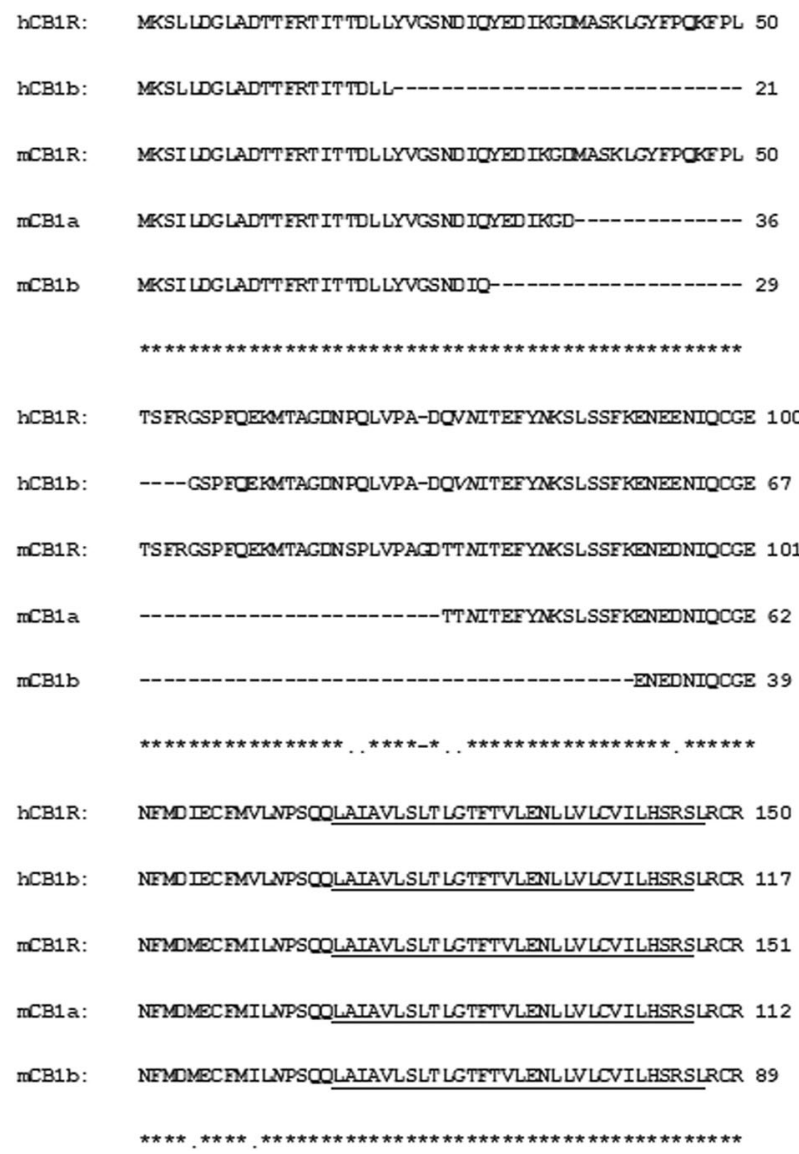

Fig. 7 Alignment of human hCB1R, hCB1a, and hCB1b with mouse mCB1a and mCB1b N-terminal variants. Identical amino acids are marked by $\left({ }^{*}\right)$, conservative changes by (.), and the gaps by dashed lines. Transmembrane domain 1 (TM1) is underlined, and a potential $\mathrm{N}$-linked glycosylation site is marked by italics $(N)$

\section{DISCUSSION}

We found no evidence of peripherally enriched rodent $C B 1 R$ isoforms, unlike the case for human-specific hCB1b [12]. We identified the potential TSSs of mouse and rat Cnr 1 exon 1 by aligning the RIKEN cap-trapper-selected EST clones [24]. Since rodent Cnr1 exons 1 and 2 can be spliced together with a retaining intron 1 (1451 bp), it is most likely that rodent $C n r 1$ has a single promoter, in contrast to rodent $\mathrm{Cnr} 2$, which has two promoters [13]. The predicted TSS and promoter regions of $\mathrm{mCB} 1$ have a high content of CpG islands $(21.8 \%$ in $1240 \mathrm{bp})$ and no TATAA boxes [40]. The putative promoter (1 kb sequence upstream flanking TSS in LASAGNA search $P \leq 0.001)$ contains binding sites for TF activator and suppressor zinc fingers (Ap1, Gata3, Esr1, Pparg, Nr3c1, Mzf1, Znf423, Znf354c, Rxra, and Ctcf), basic helix-span-helix domains (Tfap2a), rel-homology regions (Nfatc2 and Ebf1), STAT domains (Stat1 and Stat3), basic leucine zippers (Creb1 and Mafb), AT-rich interaction domains (Arid3a), and P53 domains (Tp53) $[25,26]$. The extended mCB1R exon 1 might imply that the mouse Cnr1 promoter is more upstream than previously thought, and potential transcription factors may aid in the generation of Cre-Lox recombinant knockout mice and de novo viral expression for mCB1 cell type-specific studies. We conducted a miRBase search using the mCB1 $3^{\prime}$ UTR of $3.7 \mathrm{~kb}$ sequence [27] with an E-value cutoff of 0.1 and found that a mouse mature microRNA target of $\mathrm{mCB} 1 \mathrm{R}$ (nucleotide position at NM_007726: 3688-3126) contains a cluster [41] of miR-466i-5p, miR-574-5p, and miR-1187 involved in retina disease and white adipose tissue hypertrophy $[42,43]$. The evolution of transcription factor and miRNA binding sites of rodent $\mathrm{Cnr}_{1}$ is different from that of human CNR1 [12]. The miRNAs are potentially therapeutic agents targeting the $3^{\prime}$ UTR to inhibit $\mathrm{MCB} 1 \mathrm{R}$ expression in pancreatic beta-cells and liver hepatocytes, where $\mathrm{mCB} 1 \mathrm{~A}$ expression is hundreds of times lower than in brain.

Cell type-specific expression of alternative splicing factors and binding proteins control the cell type-specific alternative splicing $[44,45]$. We found that CB1R cell type-specific alternative splicing generates different $5^{\prime}$ UTR sequences in different species, tissues, and cell types, with more isoforms expressed in brain regions. The SPRAM algorithm predicts that $\mathrm{mCB} 1 \mathrm{~A}$ and $\mathrm{rCB} 1 \mathrm{~A}$ contain one high-confidence $\mathrm{N}^{6}$-methyladenosine $\left(\mathrm{m}^{6} \mathrm{~A}\right)$ modification site that is not in the intron 1 region of $\mathrm{mCB} 1 \mathrm{~B}$ or $\mathrm{rCB} 1 \mathrm{~B}$. In contrast, the $5^{\prime}$ UTRs of hCB1R isoforms contain two high-confidence $\mathrm{m}^{6} \mathrm{~A}$ modification sites [12]. The posttranscriptional modification of $\mathrm{m}^{6} \mathrm{~A}$ is involved in the translation and alternative splicing of mRNAs [46, 47], and the species-specific $m^{6} \mathrm{~A}$ modifications indicate that the posttranscriptional $\mathrm{m}^{6} \mathrm{~A}$ modification of CBR1 is under evolutionary selection. Different CB1R 5'UTRs might also direct the receptor localization in different axon terminals, differentially target apical, or basal dendrite branches of postsynaptic neurons, and retrogradely inhibit glutamatergic and GABAergic presynaptic neurotransmitter releases [48, 49]. The spherical shape of pancreatic beta-cells and hepatocytes do not require polarized targeting of $C B 1 R$, so they contain simple $5^{\prime}$ UTR CB1R structures. Human $\mathrm{CB}_{1 \mathrm{R}_{472}}$ shares $97 \%$ identical amino acids with $\mathrm{mCB}_{1} \mathrm{R}_{473}$ and $\mathrm{rCB} 1 \mathrm{R}_{473}(99 \%$ identical between mouse and rat) in comparison, while human $\mathrm{CB}_{2} \mathrm{R}_{360}$ shares $82 \%$ and $81 \%$ identical amino acids with mCB2R 347 and rCB2 $_{360}(93 \%$ identical between mouse and rat), respectively. Evolutionarily, a single Cnr1 gene appeared first in urochordates, and gene duplication created the $C n r 2$ gene in vertebrates [50], with a more conserved CB1R but more diverse CB2R between species. CNR1 orthologs are similar in gene size $(\sim 26 \mathrm{~kb})$ between humans and rodents, but the human CNR2 orthologs are approximately 3.6 times larger $(\sim 90 \mathrm{~kb})$ than the rodent gene $(\sim 25 \mathrm{~kb})$ [15]. Intra-exonal splicing generates different CB1R N-terminal sequences between humans, mice, and rats (Fig. 7). The intra-exonal splicing generates human $\mathrm{N}$-terminal variants of $\mathrm{hCB} 1 \mathrm{a}_{411}$ with altered and shortened (deletion of 62 amino acids) $\mathrm{N}$ termini and $\mathrm{hCB} 1 \mathrm{~b}_{439}$ with a deletion of 33 amino acids from its $\mathrm{N}$ terminus [12], in contrast to the alternative splicing of $\mathrm{mCB} \mathrm{a}_{433}$ and $\mathrm{mCB}_{1} \mathrm{~b}_{411}$, which deletes 39 and 62 amino acids at their respective $\mathrm{N}$ termini. The consensus splicing donor sites of mCB1a and mCB1b change from GT to GA and TA, respectively, although splicing acceptor sites remain the consensus AG [35]. In contrast, hCB1a and hCB1b splicing donor sites and acceptor sites agree with the GT-AG consensus sequence [12]. Interestingly, the N-terminal variants of $\mathrm{rCB} 1 \mathrm{a}$ are similar to hCB1a with 62 amino acids deleted; however, the consensus splicing donor site changes from GT to $C A$, and the splicing acceptor site remains the consensus AG [51]. The expression levels of the $\mathrm{N}$-terminal spliced isoforms in different species are very low, and we did not find preferential mouse mCB1a or mCB1b Nterminal isoform expression in hepatocytes or pancreatic islets, as we did for hCB1b [12]. These N-terminal variants might be leakage splicing events or evolution pools for speciation. Therefore, lower expression of $\mathrm{mCB} 1 \mathrm{~A}$ in peripheral tissues might be a good target for morpholino antisense oligonucleotide inhibition of isoform splicing [52] without significantly affecting abundant brain mCB1R. However, rodent CB1R models might not be specific for peripheral CB1R isoform-targeted inhibition as they are for human hCB1b.

CB1R is abundant in brain, and CB2R is abundant in immune cells. However, lower levels of CB1R play important roles in peripheral tissues [53], as do low levels of CB2R in brain neurons and glia cells [54]. Relatively exclusive cell type-specific expression was observed in the ventral tegmental area, where the majority dopaminergic neurons express $\mathrm{mCB} 2$ and not $\mathrm{mCB} 1$ [55]. In this 
study, we observed co-expression of CB1R and CB2R in rat microglia cells, although the primary cultured neurons, astrocytes, and microglia had gene expression profiles that were different from those of the adult rat brain. There are more CB1R isoforms in the mouse than in the rat. In contrast, there are more CB2R isoforms in the rat than in the mouse [16]. Should there be interaction/crosstalk between CB1R and CB2R, then there are likely to be species-dependent differences. Our 3D models of peripheral restricted JD5037 binding to hCB1R indicate potential modification sites on arm 4 to improve the affinity and peripheral restriction of $C B 1 R$ ligands. The purpose of modeling $C B 1 R$ with JD5037 is to see how well it activates the peripheral enriched human $\mathrm{CB} 1 \mathrm{R}$ isoform (hCB1b) when the crystal structures of complete CB1Rs are available. The low expression of the CB1A isoform and high expression of the CB2R isoform in peripheral tissues provide attractive dual targets for cannabinoid peripheral therapeutics. Simultaneous CB1R antagonism [56] and CB2R agonism [57] may have synergistic beneficial effects [58] on aging-related metabolic and inflammatory diseases.

\section{GENBANK ACCESSION NUMBERS}

mCB1A (MH013961) and mCB1B (MH013962).

\section{ACKNOWLEDGEMENTS}

JME, Q-RL, NSH, IG-M, JFO, and SS-C-C are supported by the Intramural Research Program of the National Institute on Aging; Z-XX by the Intramural Research Program of the National Institute on Drug Abuse, National Institutes of Health; HQ by the National Science Foundation of China (31671375); ESO by NIH grant DA032890; and YW by the National Health Research Institutes and a Central Government S \& T Grant, Taiwan (106-1901-01-10-02).

\section{AUTHOR CONTRIBUTIONS}

$\mathrm{Q}-\mathrm{RL}, \mathrm{ESO}$, and JME conceptualized the study and wrote the manuscript. Q-RL, JME, JFO, IG-M, MD, and SS-C-C performed S961 treatment and mouse and rat tissue dissections. Q-RL and $\mathrm{HQ}$ analyzed the gene structures and protein modeling, respectively, using the bioinformatics tools. Q-RL, NSH, and Z-XX performed RT-qPCR, RNAscope $\mathrm{ISH}$, imaging, and data analysis. Primary cell culture and isolation of neurons, astrocytes, and microglia were conducted by YW. All authors reviewed and approved the publication of this manuscript.

\section{ADDITIONAL INFORMATION}

Competing interests: The authors declare no competing interests.

\section{REFERENCES}

1. Mechoulam R, Parker LA. The endocannabinoid system and the brain. Annu Rev Psychol. 2013;64:21-47.

2. Nathan PJ, O'Neill BV, Napolitano A, Bullmore ET. Neuropsychiatric adverse effects of centrally acting antiobesity drugs. CNS Neurosci Ther. 2011;17:490-505.

3. Gonzalez-Mariscal I, Krzysik-Walker SM, Kim W, Rouse M, Egan JM. Blockade of cannabinoid 1 receptor improves GLP-1R mediated insulin secretion in mice. Mol Cell Endocrinol. 2016:423:1-10.

4. Perwitz N, Wenzel J, Wagner I, Buning J, Drenckhan M, Zarse K, et al. Cannabinoid type 1 receptor blockade induces transdifferentiation towards a brown fat phenotype in white adipocytes. Diabetes Obes Metab. 2010;12:158-66.

5. Udi S, Hinden L, Earley B, Drori A, Reuveni N, Hadar R, et al. Proximal tubular cannabinoid-1 receptor regulates obesity-induced CKD. J Am Soc Nephrol. 2017;28:3518-32.

6. Liu J, Zhou L, Xiong K, Godlewski G, Mukhopadhyay B, Tam J, et al. Hepatic cannabinoid receptor-1 mediates diet-induced insulin resistance via inhibition of insulin signaling and clearance in mice. Gastroenterology. 2012;142:1218-28 e1.

7. Ruiz de Azua I, Mancini G, Srivastava RK, Rey AA, Cardinal P, Tedesco L, et al. Adipocyte cannabinoid receptor $\mathrm{CB} 1$ regulates energy homeostasis and alternatively activated macrophages. J Clin Invest. 2017;127:4148-62.

8. Jalin AM, Rajasekaran M, Prather PL, Kwon JS, Gajulapati V, Choi Y, et al. Nonselective cannabinoid receptor antagonists, hinokiresinols reduce infiltration of microglia/macrophages into ischemic brain lesions in rat via modulating 2-arachidonolyglycerol-induced migration and mitochondrial activity. PLoS One. 2015;10:e0141600.

9. Mai P, Yang L, Tian L, Wang L, Jia S, Zhang Y, et al. Endocannabinoid system contributes to liver injury and inflammation by activation of bone marrowderived monocytes/macrophages in a CB1-dependent manner. J Immunol. 2015;195:3390-401.

10. MCPartland JM. Phylogenomic and chemotaxonomic analysis of the endocannabinoid system. Brain Res Brain Res Rev. 2004;45:18-29.

11. McPartland JM, Glass M, Pertwee RG. Meta-analysis of cannabinoid ligand binding affinity and receptor distribution: interspecies differences. $\mathrm{Br} J$ Pharmacol. 2007;152:583-93.

12. Gonzalez-Mariscal I, Krzysik-Walker SM, Doyle ME, Liu QR, Cimbro R, Santa-Cruz Calvo S, et al. Human CB1 receptor isoforms, present in hepatocytes and betacells, are involved in regulating metabolism. Sci Rep. 2016;6:33302.

13. Liu QR, Pan $\mathrm{CH}$, Hishimoto $\mathrm{A}$, Li CY, Xi ZX, Llorente-Berzal $\mathrm{A}$, et al. Species differences in cannabinoid receptor 2 (CNR2 gene): identification of novel human and rodent $\mathrm{CB} 2$ isoforms, differential tissue expression and regulation by cannabinoid receptor ligands. Genes Brain Behav. 2009;8:519-30.

14. Zhang PW, Ishiguro $H$, Ohtsuki T, Hess J, Carillo F, Walther D, et al. Human cannabinoid receptor $1: 5^{\prime}$ exons, candidate regulatory regions, polymorphisms, haplotypes and association with polysubstance abuse. Mol Psychiatry. 2004;9:916-31.

15. Onaivi ES, Ishiguro $H, G u S$, Liu QR. CNS effects of CB2 cannabinoid receptors: beyond neuro-immuno-cannabinoid activity. J Psychopharmacol. 2012;26: 92-103.

16. Zhang HY, Bi GH, Li X, Li J, Qu H, Zhang SJ, et al. Species differences in cannabinoid receptor 2 and receptor responses to cocaine self-administration in mice and rats. Neuropsychopharmacology. 2015;40:1037-51.

17. Chiang YC, Lo YN, Chen JC. Crosstalk between dopamine $D(2)$ receptors and cannabinoid $\mathrm{CB}(1)$ receptors regulates CNR1 promoter activity via ERK1/2 signaling. J Neurochem. 2013;127:163-76.

18. Iyer MR, Cinar R, Coffey NJ, Chorvat RJ, Kunos G. Synthesis of S-2-((S)-3-(4chlorophenyl)- $\mathrm{N}^{\prime}$-((4-chlorophenyl)sulfonyl)-4-phenyl-4,5-dihydro-1H-pyrazole-1carboximidamido)-3-(methyl-d3)butanamide-d5, octadeuterated JD5037. J Label Comp Radiopharm. 2017;60:460-5.

19. Hua T, Vemuri K, Nikas SP, Laprairie RB, Wu Y, Qu L, et al. Crystal structures of agonist-bound human cannabinoid receptor CB1. Nature. 2017;547:468-71.

20. Hua T, Vemuri K, Pu M, Qu L, Han GW, Wu Y, et al. Crystal structure of the human cannabinoid receptor CB1. Cell. 2016;167:750-62 e14.

21. Liu QR, Rubio FJ, Bossert JM, Marchant NJ, Fanous S, Hou X, et al. Detection of molecular alterations in methamphetamine-activated Fos-expressing neurons from a single rat dorsal striatum using fluorescence-activated cell sorting (FACS). J Neurochem. 2014;128:173-85.

22. Harvey BK, Chou J, Shen H, Hoffer BJ, Wang Y. Diadenosine tetraphosphate reduces toxicity caused by high-dose methamphetamine administration. Neurotoxicology. 2009;30:436-44.

23. Zhang C, Deng Y, Dai H, Zhou W, Tian J, Bing G, et al. Effects of dimethyl sulfoxide on the morphology and viability of primary cultured neurons and astrocytes. Brain Res Bull. 2017;128:34-9.

24. Carninci $P$, Shibata $Y$, Hayatsu N, Sugahara $Y$, Shibata $K$, Itoh $M$, et al. Normalization and subtraction of cap-trapper-selected cDNAs to prepare full-length CDNA libraries for rapid discovery of new genes. Genome Res. 2000;10:1617-30.

25. Lee $\mathrm{C}$, Huang $\mathrm{CH}$. LASAGNA-Search: an integrated web tool for transcription factor binding site search and visualization. Biotechniques. 2013;54:141-53.

26. Khan A, Fornes $O$, Stigliani A, Gheorghe M, Castro-Mondragon JA, van der Lee $R$, et al. JASPAR 2018: update of the open-access database of transcription factor binding profiles and its web framework. Nucleic Acids Res. 2017:46:D1284.

27. Kozomara A, Griffiths-Jones S. miRBase: integrating microRNA annotation and deep-sequencing data. Nucleic Acids Res. 2011;39:D152-7.

28. Zhou Y, Zeng P, Li YH, Zhang Z, Cui Q. SRAMP: prediction of mammalian N6methyladenosine (m6A) sites based on sequence-derived features. Nucleic Acids Res. 2016:44:e91.

29. Pettersen EF, Goddard TD, Huang CC, Couch GS, Greenblatt DM, Meng EC, et al. UCSF Chimera-a visualization system for exploratory research and analysis. J Comput Chem. 2004;25:1605-12.

30. Morris GM, Huey R, Lindstrom W, Sanner MF, Belew RK, Goodsell DS, et al. AutoDock4 and AutoDockTools4: automated docking with selective receptor flexibility. J Comput Chem. 2009;30:2785-91.

31. Abood ME, Ditto KE, Noel MA, Showalter VM, Tao Q. Isolation and expression of a mouse $\mathrm{CB} 1$ cannabinoid receptor gene. Comparison of binding properties with those of native CB1 receptors in mouse brain and N18TG2 neuroblastoma cells. Biochem Pharmacol. 1997;53:207-14.

32. McCaw EA, Hu H, Gomez GT, Hebb AL, Kelly ME, Denovan-Wright EM. Structure, expression and regulation of the cannabinoid receptor gene (CB1) in Huntington's disease transgenic mice. Eur J Biochem. 2004:271:4909-20. 
33. Pruitt KD, Tatusova T, Maglott DR. NCBI Reference Sequence (RefSeq): a curated non-redundant sequence database of genomes, transcripts and proteins. Nucleic Acids Res. 2005;33:D501-4.

34. Bonaldo MF, Lennon G, Soares MB. Normalization and subtraction: two approaches to facilitate gene discovery. Genome Res. 1996;6:791-806.

35. Ruehle S, Wager-Miller J, Straiker A, Farnsworth J, Murphy MN, Loch S, et al. Discovery and characterization of two novel CB1 receptor splice variants with modified N-termini in mouse. J Neurochem. 2017;142:521-33.

36. Gonzalez-Mariscal I, Montoro RA, Doyle ME, Liu QR, Rouse M, O'Connell JF, et al. Absence of cannabinoid 1 receptor in beta cells protects against high-fat/highsugar diet-induced beta cell dysfunction and inflammation in murine islets. Diabetologia. 2018;61:1470-83.

37. Matsuda LA, Lolait SJ, Brownstein MJ, Young AC, Bonner TI. Structure of a cannabinoid receptor and functional expression of the cloned cDNA. Nature. 1990;346:561-4.

38. McLaughlin CR, Martin BR, Compton DR, Abood ME. Cannabinoid receptors in developing rats: detection of mRNA and receptor binding. Drug Alcohol Depend. 1994;36:27-31.

39. Shao Z, Yin J, Chapman K, Grzemska M, Clark L, Wang J, et al. High-resolution crystal structure of the human CB1 cannabinoid receptor. Nature. 2016;540:602-6.

40. Gardiner-Garden M, Frommer M. CpG islands in vertebrate genomes. J Mol Biol. 1987;196:261-82.

41. Zheng GX, Ravi A, Gould GM, Burge CB, Sharp PA. Genome-wide impact of a recently expanded microRNA cluster in mouse. Proc Natl Acad Sci U S A. 2011;108:15804-9.

42. Belarbi Y, Mejhert N, Gao H, Arner P, Ryden M, Kulyte A. MicroRNAs-361-5p and miR-574-5p associate with human adipose morphology and regulate EBF1 expression in white adipose tissue. Mol Cell Endocrinol. 2017;472:50-6.

43. Olivares AM, Jelcick AS, Reinecke J, Leehy B, Haider A, Morrison MA, et al. Multimodal regulation orchestrates normal and complex disease states in the retina. Sci Rep. 2017;7:690.

44. Allen SE, Toro CP, Andrade A, Lopez-Soto EJ, Denome S, Lipscombe D. Cellspecific RNA binding protein Rbfox2 regulates CaV2.2 mRNA exon composition and CaV2.2 current size.eNeuro.2017;4:pii: ENEURO.0332-16.2017

45. lijima $T$, lijima $Y$, Witte $H$, Scheiffele $P$. Neuronal cell type-specific alternative splicing is regulated by the KH domain protein SLM1. J Cell Biol. 2014;204:331-42.
46. Adhikari S, Xiao W, Zhao YL, Yang YG. m(6)A: signaling for mRNA splicing. RNA Biol. 2016;13:756-9.

47. Patil DP, Pickering BF, Jaffrey SR. Reading $m(6) A$ in the transcriptome: $m(6) A$ binding proteins. Trends Cell Biol. 2018;28:113-27.

48. Liu QR, Lu L, Zhu XG, Gong JP, Shaham Y, Uhl GR. Rodent BDNF genes, novel promoters, novel splice variants, and regulation by cocaine. Brain Res. 2006;1067:1-12.

49. Maynard KR, Hobbs JW, Sukumar M, Kardian AS, Jimenez DV, Schloesser RJ, et al Bdnf mRNA splice variants differentially impact CA1 and CA3 dendrite complexity and spine morphology in the hippocampus. Brain Struct Funct. 2017;222:3295-307.

50. Elphick MR. Evolution of cannabinoid receptors in vertebrates: identification of a $\mathrm{CB}(2)$ gene in the puffer fish Fugu rubripes. Biol Bull. 2002;202:104-7.

51. Shire D, Calandra B, Rinaldi-Carmona M, Oustric D, Pessegue B, Bonnin-Cabanne $\mathrm{O}$, et al. Molecular cloning, expression and function of the murine $C B 2$ peripheral cannabinoid receptor. Biochim Biophys Acta. 1996;1307:132-6.

52. Vijayakumar S, Depreux FF, Jodelka FM, Lentz JJ, Rigo F, Jones TA, et al. Rescue of peripheral vestibular function in Usher syndrome mice using a splice-switching antisense oligonucleotide. Hum Mol Genet. 2017;26:3482-94.

53. Tam J, Liu J, Mukhopadhyay B, Cinar R, Godlewski G, Kunos G. Endocannabinoids in liver disease. Hepatology. 2011;53:346-55.

54. Zhang HY, Gao M, Liu QR, Bi GH, Li X, Yang HJ, et al. Cannabinoid CB2 receptors modulate midbrain dopamine neuronal activity and dopamine-related behavior in mice. Proc Natl Acad Sci U S A. 2014;111:E5007-15.

55. Liu QR, Canseco-Alba A, Zhang HY, Tagliaferro P, Chung M, Dennis E, et al. Cannabinoid type 2 receptors in dopamine neurons inhibits psychomotor behaviors, alters anxiety, depression and alcohol preference. Sci Rep. 2017; 7:17410.

56. Tam J, Szanda G, Drori A, Liu Z, Cinar R, Kashiwaya Y, et al. Peripheral cannabinoid-1 receptor blockade restores hypothalamic leptin signaling. Mol Metab. 2017;6:1113-25.

57. Lin X, Dhopeshwarkar AS, Huibregtse M, Mackie K, Hohmann AG. Slowly signaling $G$ protein-biased CB2 cannabinoid receptor agonist LY2828360 suppresses neuropathic pain with sustained efficacy and attenuates morphine tolerance and dependence. Mol Pharmacol. 2018;93:49-62.

58. Rowley S, Sun X, Lima IV, Tavenier A, de Oliveira ACP, Dey SK, et al. Cannabinoid receptor 1/2 double-knockout mice develop epilepsy. Epilepsia. 2017;58:e162-e6. 